Article

\title{
Astragaloside IV Promotes Adult Neurogenesis in Hippocampal Dentate Gyrus of Mouse through CXCL1/CXCR2 Signaling
}

\author{
Fei Huang ${ }^{\dagger}$, Yunyi Lan ${ }^{\dagger}$, Liyue Qin, Huaihuai Dong, Hailian Shi, Hui Wu, Qinrui Zou, \\ Zhibi $\mathrm{Hu}^{*}$ and Xiaojun $\mathrm{Wu}$ *
}

\begin{abstract}
Shanghai Key Laboratory of Compound Chinese Medicines, The Ministry of Education (MOE) Key Laboratory for Standardization of Chinese Medicines, The State Administration of TCM (SATCM) Key Laboratory for New Resources and Quality Evaluation of Chinese Medicine, Institute of Chinese Materia Medica, Shanghai University of Traditional Chinese Medicine, Shanghai 201203, China; Fei_H@hotmail.com (F.H.); ddlanyunyi@126.com (Y.L.); 13774474958@163.com (L.Q.); 13917511681@163.com (H.D.);

shihailian2003@163.com (H.S.); zgykdxwuhui@foxmail.com (H.W.); zqr314@hotmail.com (Q.Z.)

* Correspondence: huzhibi@hotmail.com (Z.H.); xiaojunwu@shutcm.edu.cn (X.W.);

Tel./Fax: +86-021-5132-2638 (Z.H.); +86-021-5132-2578 (Z.W.)

t These authors contribute equally to this work.
\end{abstract}

Received: 15 August 2018; Accepted: 27 August 2018; Published: 29 August 2018

\begin{abstract}
Astragaloside IV (ASI) has been reported to promote neural stem cells proliferation in vitro and CXCR2 expression on neutrophils. The present study was aimed to investigate the influence of ASI on adult neurogenesis in hippocampal dentate gyrus (DGs) of mouse and to discuss the possible underlying mechanisms. Total number of proliferative cells $\left(\mathrm{BrdU}^{+}\right)$, pre-mature neurons $\left(\mathrm{DCX}^{+}\right)$, early proliferative cells $\left(\mathrm{BrdU}^{+} / \mathrm{DCX}^{+}\right)$, proliferative radial gila-like cells $\left(\mathrm{BrdU}^{+} / \mathrm{GFAP}^{+}\right)$ and newly generated neurons $\left(\mathrm{BrdU}^{+} / \mathrm{NeuN}^{+}\right)$after $\mathrm{ASI}$ or vehicle administration for two weeks were counted, respectively. The results showed that $\mathrm{BrdU}^{+}$cells and $\mathrm{DCX}^{+}$cells were significantly increased in DGs of mice administered with ASI. The numbers of $\mathrm{BrdU}^{+} / \mathrm{DCX}^{+}, \mathrm{BrdU}^{+} / \mathrm{GFAP}^{+}$ cells and $\mathrm{BrdU}^{+} / \mathrm{NeuN}^{+}$cells were also elevated in the ASI group. Correspondingly, ASI increased the protein expression of hippocampal DCX, GFAP and NeuN. Further study disclosed that ASI remarkably up-regulated the mRNA and protein expressions of CXCL1 as well as that of CXCR2 in the hippocampus. The promotive effect of ASI on DCX, GFAP and NeuN protein expression was abolished by SB225002, the inhibitor of CXCR2. Our results indicated that ASI modulated the homeostasis of the CXCL1/CXCR2 signaling pathway, which might be responsible for the increased neurogenesis within the hippocampal DGs of mice.
\end{abstract}

Keywords: astragaloside IV; neurogenesis; CXCL1/CXCR2; early proliferative cells; proliferative radial gila-like cells; newly generated neurons

\section{Introduction}

Adult hippocampal neurogenesis attracts specific attention as it is suggested to play an important role in higher cognitive function, most notably memory processes, and certain affective behaviors [1]. Lateral ventricles and hippocampal dentate gyrus (DG) are the well-known regions in the brain where the neural progenitor cells proliferate and differentiate into mature neurons throughout the lifetime of animals [2,3]. In the hippocampus, the mature neurons can consolidate surrounding structures and participate in many critical processes such as learning and memory [4]. Accumulative evidence shows that adult neurogenesis is essential for specific types of hippocampus-dependent learning [5-7]. 
Chemokines (chemotactic cytokines) compose a family of small protein ligands involved in leukocyte migration and communication [8]. Interestingly, chemokines and their receptors are expressed in all major types of cells in the central nervous system (CNS), and a growing body of evidence suggests that chemokines and their receptors also mediate the cellular communication in CNS [9]. For instance, CXCR2 has been shown to enhance the survival of hippocampal neurons [10,11], and is involved in patterning the spinal cord by controlling the position of oligodendrocyte precursors after stimulation by its ligand CXCL1 [12].

Astragaloside IV (ASI) is one of the major active saponins in Astragalus membranaceus (Fisch) Bge, a widely used herb in China for the treatment of cardiovascular, hepatic, and renal disorders [13]. Several studies demonstrated that ASI has a prominent antioxidant effect shown by inhibition of the generation of reactive oxygen species (ROS) [14], reduction of lipid peroxidation [15], and elevation of antioxidant enzymes [16]. It exerts neuroprotective effects against ischemic brain injury by anti-oxidation [17], anti-inflammation [18], anti-apoptosis [19] and blood-brain barrier protection [20]. In addition, our studies demonstrated that it can attenuate experimental autoimmune encephalomyelitis in mice by counteracting oxidative stress at multiple levels [21]. Recently, it was reported that ASI ameliorates the learning and memory deficit in rats after chronic cerebral hypoperfusion [22] and attenuates cognitive impairments induced by transient cerebral ischemia and reperfusion in mice [23]. Moreover, ASI promotes neural stem cells proliferation and differentiation [24]. An in vitro study showed that application of ASI apparently promotes CXCR2 expression on LPS-induced neutrophils [25]. However, whether ASI can benefit neurogenesis in vivo has not been demonstrated yet.

In the present study, the effect of ASI on neurogenesis in the DGs of mice was investigated by bromodeoxyuridine (BrdU) assay. Serial brain sections from mice were then double stained with antibodies against BrdU ${ }^{+}$doublecortin (DCX, a pre-mature neuron marker), BrdU ${ }^{+}$glial fibrillary acidic protein (GFAP, an astroglial marker) or $\mathrm{BrdU}^{+}$neuronal nuclei (NeuN, a neuronal marker). Meanwhile, hippocampal expressions of genes related with neurogenesis were analyzed with the PCR array method and confirmed by real-time PCR. The results showed that ASI actively participated in hippocampal neurogenesis, which was closely associated with enhanced CXCL1/CXCR2 signaling transduction. The study deepened our understanding of the role of ASI in the dynamic and complex process of neurogenesis that is connected to the normal brain function.

\section{Results}

\subsection{ASI Increased the Total Number of Proliferative Cells $\left(\mathrm{BrdU}^{+}\right)$, Pre-Mature Neurons $\left(\mathrm{DCX} \mathrm{X}^{+}\right)$and Early} Proliferative Cells $\left(\mathrm{BrdU}^{+} / \mathrm{DCX} \mathrm{X}^{+}\right)$

For neurogenesis analysis, BrdU-immunopositive cells and DCX-immunopositive cells were counted firstly. The DGs of ASI group mice contained more BrdU-immunopositive cells (Control vs. ASI, respectively, $n=4$ per group, $p<0.05$ ) (Figure $1 \mathrm{~A}, \mathrm{D}, \mathrm{G}, \mathrm{J}$ ) and DCX-immunopositive cells (Control vs. ASI, respectively, $n=4$ per group, $p<0.05$ ) (Figure $1 \mathrm{~B}, \mathrm{E}, \mathrm{H}, \mathrm{K}$ ) compared to that of their controls. Moreover, double immunopositive $\left(\mathrm{BrdU}^{+} / \mathrm{DCX}^{+}\right)$cells showed a difference between two groups (Control vs. ASI, respectively, $n=4$ per group, $p<0.05$ ) (Figure 1C,F,I,L). Moreover, the total amount of DCX protein was elevated in the hippocampus of ASI group mice ( $n=8$ per group) (Figure $1 \mathrm{M}, \mathrm{N}$ ). These results indicated that ASI increased proliferative cells, pre-mature neurons and early proliferative cells. 

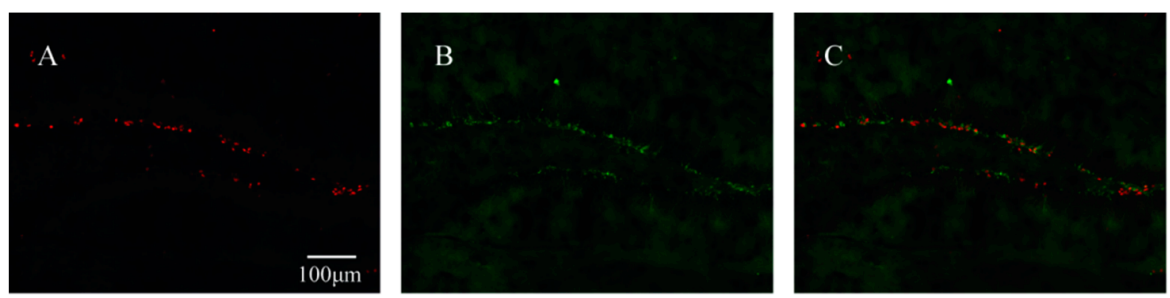

Control

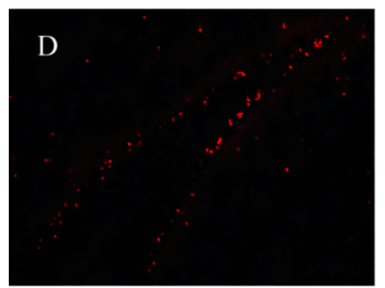

BrdU
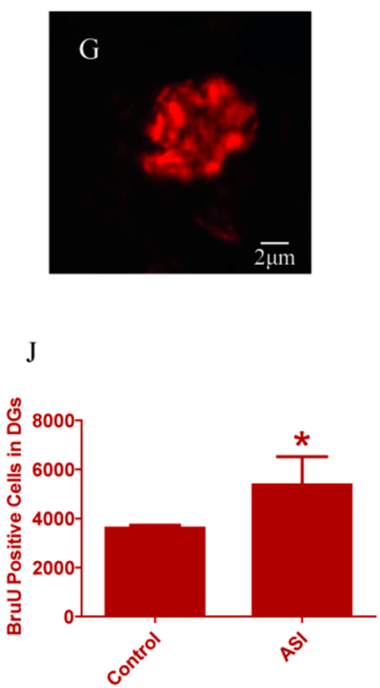

K

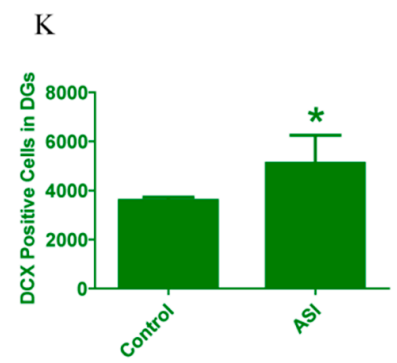

M

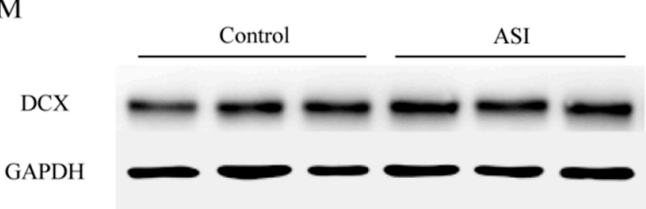

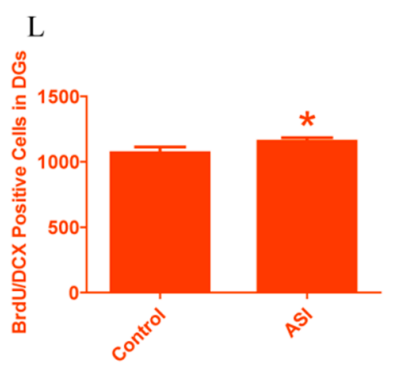

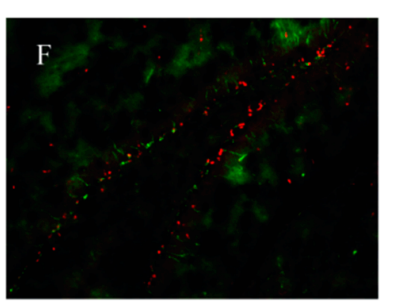

Merge

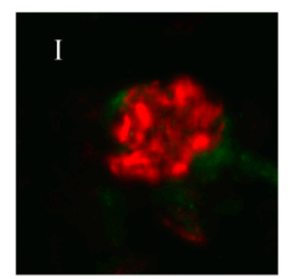

$\mathrm{N}$

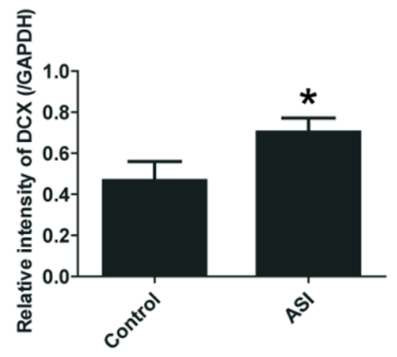

Figure 1. ASI $(25 \mathrm{mg} / \mathrm{kg})$ increased the total number of proliferative cells $\left(\mathrm{BrdU}^{+}\right)$, pre-mature neurons $\left(\mathrm{DCX}^{+}\right)$and early proliferative cells $\left(\mathrm{BrdU}^{+} / \mathrm{DCX}^{+}\right)$. (A-I) Confocal images of BrdU (red) and DCX (green) immunostaining: (A-C) control group; (D-F) ASI group; and (G-I) enlarged images of the cells from ASI group. (A-F) Scale bar $=100 \mu \mathrm{m}$. (G-I) Scale bar $=2 \mu \mathrm{m}$. (J-L) Quantification of BrdU ${ }^{+}$, $\mathrm{DCX}^{+}$and $\mathrm{BrdU}^{+} / \mathrm{DCX}^{+}$immunopositive cells in two groups ( $n=4$ /group). (M) Western blotting analysis of DCX in hippocampus. (N) Gray intensity analysis of DCX in hippocampus ( $n=8 /$ group). ${ }^{*} p<0.05$. The data are presented as mean $\pm \mathrm{SD}$.

\subsection{ASI Increased the Total Number of Proliferative Radial Glia-Like Cells $\left(\mathrm{BrdU}^{+} / \mathrm{GFAP}^{+}\right)$and Newly} Generated Neurons $\left(\mathrm{BrdU}^{+} / \mathrm{NeuN} \mathrm{N}^{+}\right)$

To examine the effect of ASI on proliferative radial glia-like cells and newly generated neurons in DGs, $\mathrm{BrdU}^{+} / \mathrm{GFAP}^{+}$and $\mathrm{BrdU}^{+} / \mathrm{NeuN}^{+}$immunopositive cells were counted, respectively. Confocal 
microscopic results showed that $\mathrm{GFAP}^{+}$and $\mathrm{NeuN}^{+}$cells were abundant in the granular cell layer of the DGs in both groups (Figure 2B,E,H and Figure 3B,E,H). Meanwhile, the numbers of BrdU ${ }^{+}$ cells with GFAP (Control vs. ASI group, respectively, $n=4$ per group, $p<0.05$ ) (Figure $2 \mathrm{C}, \mathrm{F}, \mathrm{I}, \mathrm{J}$ ) and NeuN (Control vs. ASI group, respectively, $n=4$ per group, $p<0.05$ ) (Figure 3 C,F,I,J) expression were significantly increased in the ASI group mice. Consistently, the total amount of GFAP and NeuN proteins were also elevated remarkably in the hippocampus in ASI group mice $(n=8$ per group, $p<0.05$ ) (Figure $2 \mathrm{~K}, \mathrm{~L}$ and Figure $3 \mathrm{~K}, \mathrm{~L}$ ). These results indicated that ASI increased proliferative gila-like cells and newly generated neurons in the subgranular zone (SGZ).

In summary, all above results suggested that ASI increased adult neurogenesis at multiple levels in DGs (Figure 4).
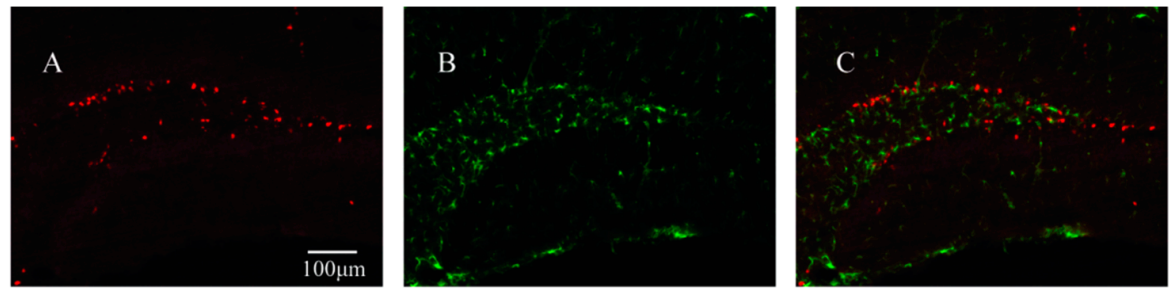

Control
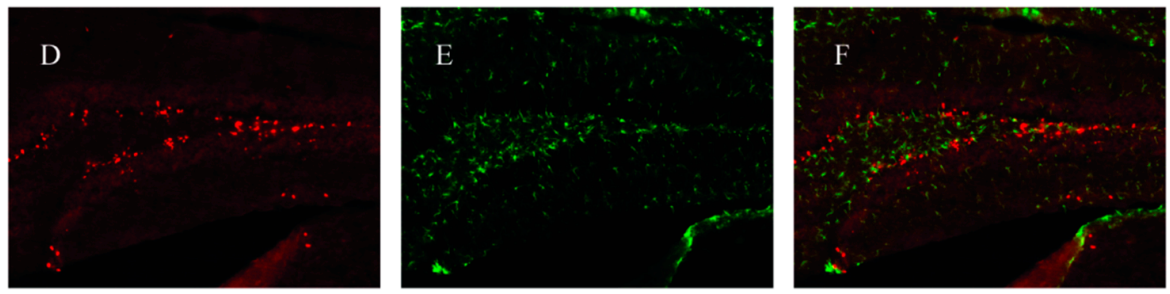

BrdU

GFAP

Merge

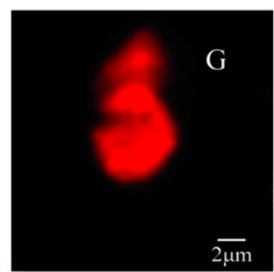

BrdU

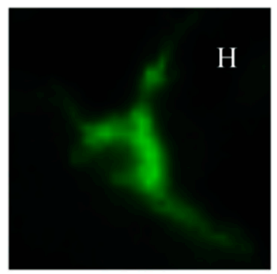

GFAP

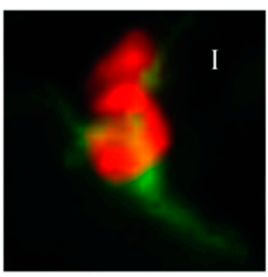

Merge

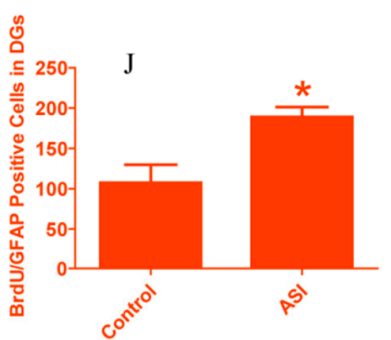

K

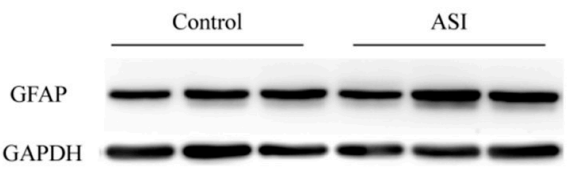

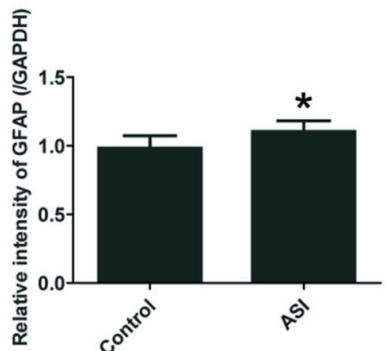

Figure 2. ASI $(25 \mathrm{mg} / \mathrm{kg})$ increased the total number of proliferative radial glia-like cells $\left(\mathrm{BrdU}^{+} / \mathrm{GFAP}^{+}\right)$. (A-I) Confocal images of BrdU (red) and GFAP (green) immunostaining: (A-C) Control group; (D-F) ASI group; and (G-I) enlarged images of the cells from ASI group. (A-F) Scale bar $=100 \mu \mathrm{m}$. (G-I) Scale bar $=2 \mu \mathrm{m}$. (J) Quantification of $\mathrm{BrdU}^{+} / \mathrm{GFAP}^{+}$double immunopositive cells in two groups ( $n=4$ /group). (K) Western blotting analysis of GFAP in hippocampus. (L) Gray intensity analysis of GFAP in hippocampus ( $n=8 /$ group). ${ }^{*} p<0.05$. The data are presented as mean $\pm \mathrm{SD}$. 

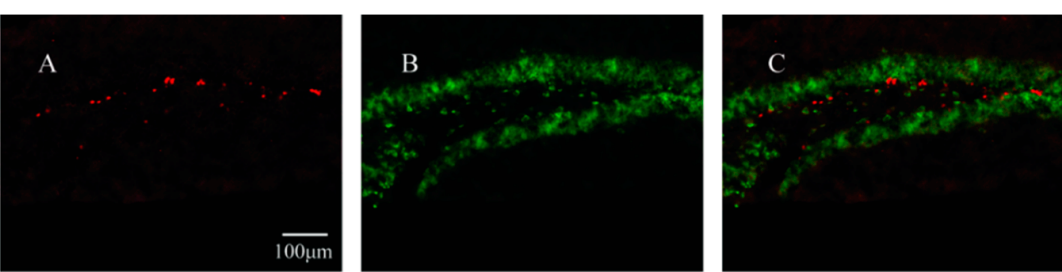

Control

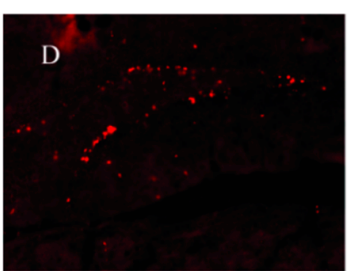

BrdU

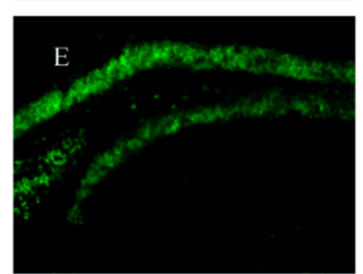

NeuN

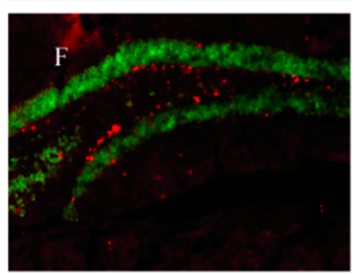

Merge

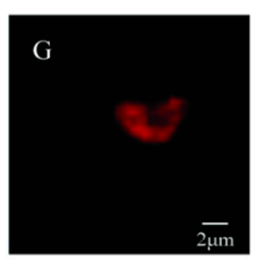

BrdU

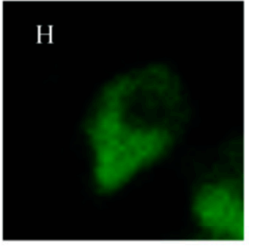

NeuN

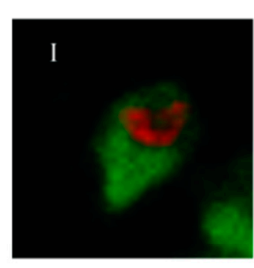

Merge

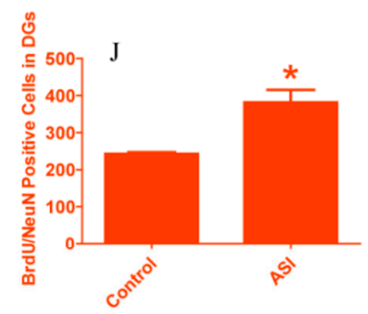

$$
\text { K }
$$

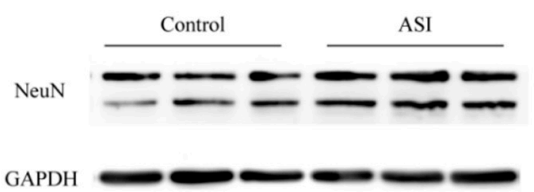

$\mathrm{L}$

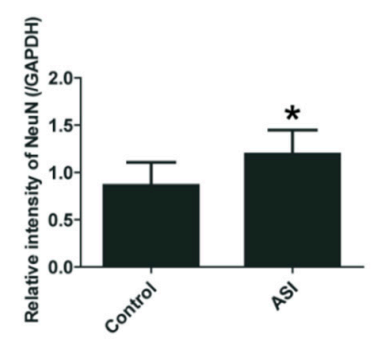

Figure 3. ASI $(25 \mathrm{mg} / \mathrm{kg})$ increased the total number of newly generated neurons $\left(\mathrm{BrdU}^{+} / \mathrm{NeuN}^{+}\right)$. (A-I) Confocal images of BrdU (red) and NeuN (green) immunostaining: (A-C) Control group; (D-F) ASI group; and (G-I) enlarged images of the cells from ASI group. (A-F) Scale bar $=100 \mu \mathrm{m}$. (G-I) Scale bar $=2 \mu \mathrm{m}$. (J) Quantification of $\mathrm{BrdU}^{+} / \mathrm{NeuN}^{+}$double immunopositive cells in two groups $(n=$ 4/group). (K) Western blotting analysis of NeuN in hippocampus. (L) Gray intensity analysis of NeuN in hippocampus ( $n=8$ /group). ${ }^{*} p<0.05$. The data are presented as mean \pm SD.

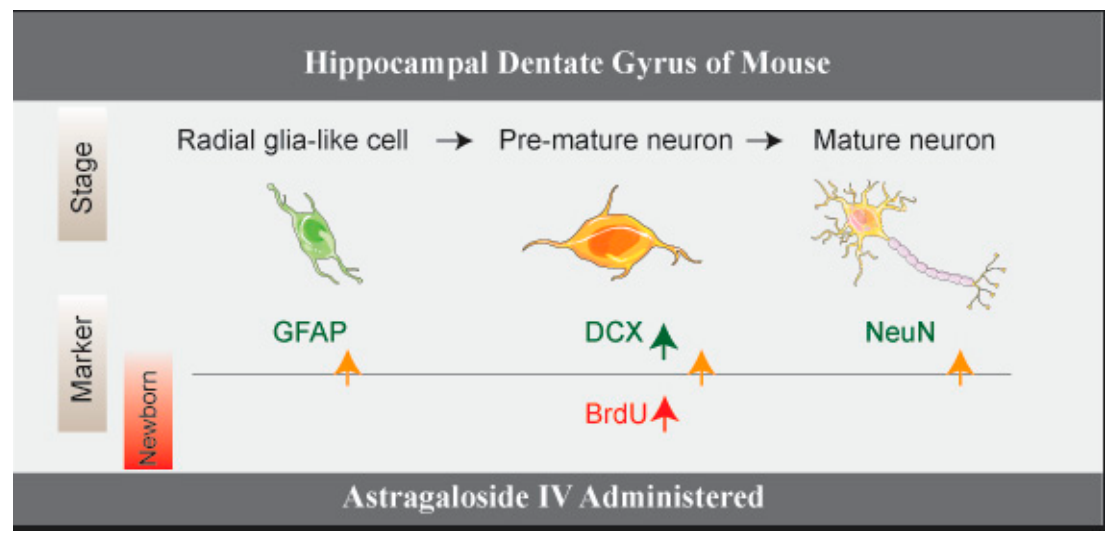

Figure 4. The schematic illustration of the promotive effect of ASI $(25 \mathrm{mg} / \mathrm{kg})$ on adult neurogenesis in DGs. 


\subsection{ASI Enhanced CXCL1/CXCR2 Signaling Pathway}

The pathways involved in neurogenesis in mouse hippocampus by ASI were investigated in a pilot study including 84 neurogenesis-related genes (Figure 5 and Table 1). The preliminary data showed that mRNA of eight genes were differently expressed after ASI treatment judged by $p$-value (Figure 5A-C). However, further quantitative PCR did not perfectly corroborate the significant fold-change of these genes (Figure 5D) as only CXCL1 displayed a 3.4-fold elevation. In addition, ASI promoted the protein expression of CXCL1 in mouse serum and hippocampus (Figure 6A,B). Since CXCL1 signals through its receptor CXCR2, the mRNA and protein expressions of the receptor were examined. Not surprisingly, hippocampal CXCR2 mRNA and protein expressions were markedly up-regulated by ASI compared to the control (Figure $6 \mathrm{C}-\mathrm{E}$ ). These results suggested the modulation of ASI on CXCL1/CXCR2 signaling pathway.

A
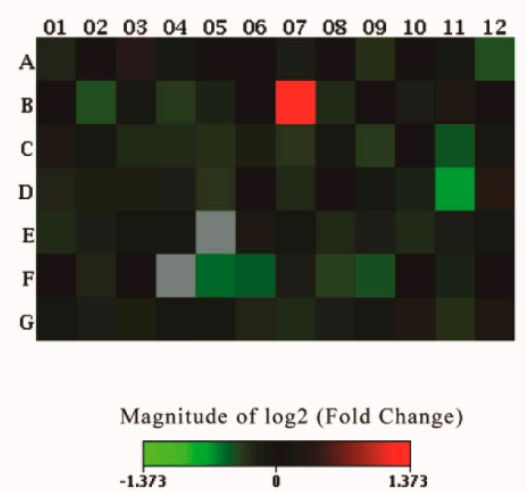

$\mathrm{C}$

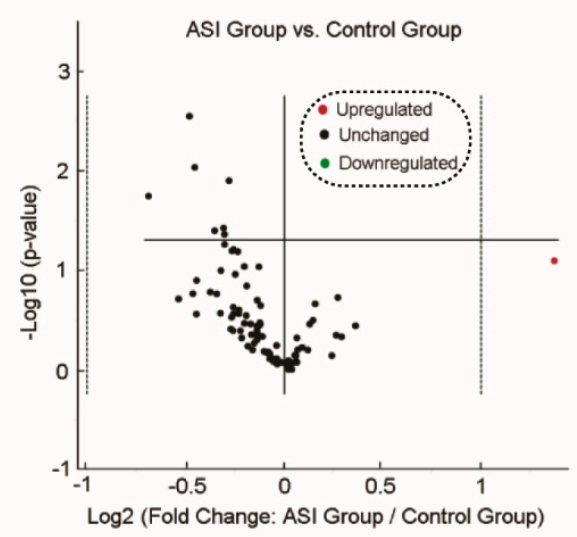

B

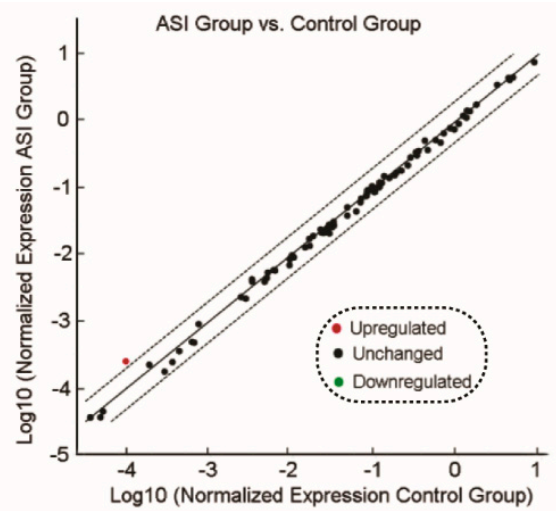

D

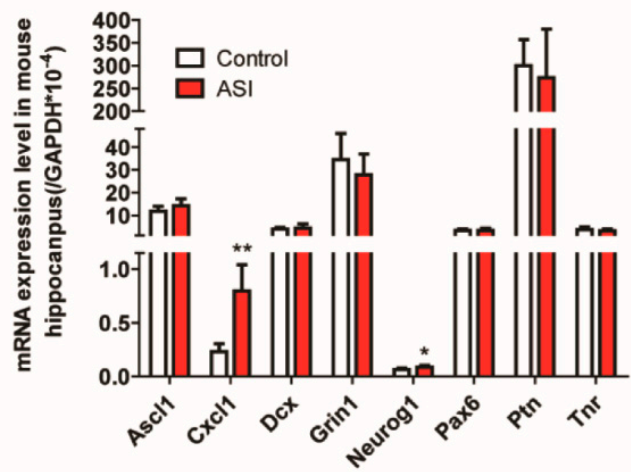

Figure 5. The effect of ASI ( $25 \mathrm{mg} / \mathrm{kg}$ ) on eighty-four neurogenesis related genes. (A) The heat map provides a graphical representation of fold change between two groups overlaid onto PCRarray plate layout; (B) The scatter plot compares the normalized expression of every gene on the array between two groups by plotting one against another to quickly visualize gene expression changes. The central line indicated unchanged gene expression; (C) The volcano plot displays statistical significance versus fold-change on the $y$ - and $x$-axes, respectively, enabling identification of genes with significant changes; (D) Verification of mRNA expression levels in mouse hippocampus; $n=6$ /group. ${ }^{*} p<0.05 ;{ }^{* *} p<0.01$. The data are presented as mean \pm SD. 
A

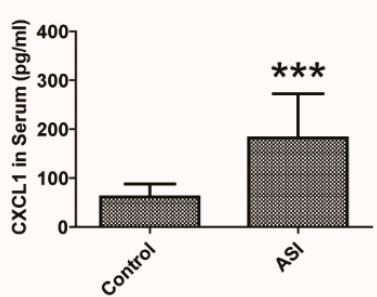

C

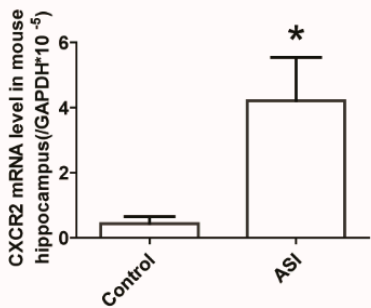

B

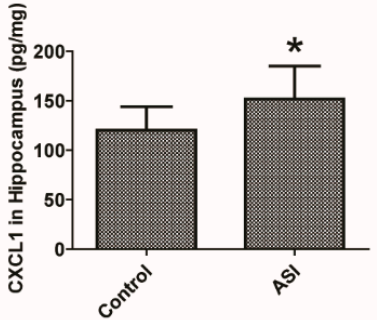

D

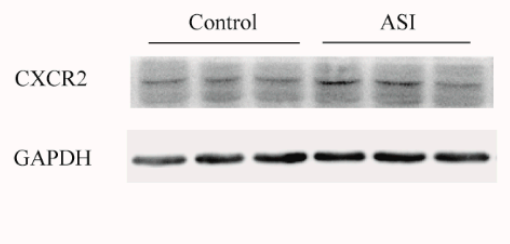

E

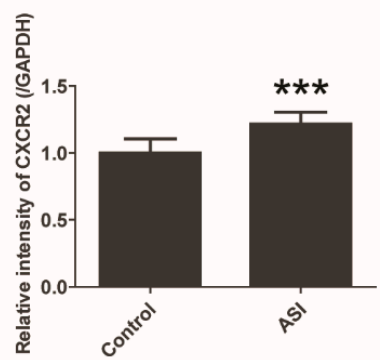

Figure 6. ASI ( $25 \mathrm{mg} / \mathrm{kg})$ promoted neurogenesis through CXCL1/CXCR2 signaling pathway. (A,B) ASI promoted protein expression of CXCL1 in mouse serum and hippocampus ( $n=10$ /group); (C) ASI enhanced CXCR2 mRNA expression level in mouse hippocampus ( $n=6$ /group); (D) Western blotting analysis of CXCR2 in hippocampus; (E) Gray intensity analysis of CXCR2 in the hippocampus of mice ( $n=8$ /group). ${ }^{*} p<0.05 ;{ }^{* *} p<0.001$. The data are presented as mean $\pm \mathrm{SD}$.

Table 1. The effect of ASI on mRNA expressions of eighty-four neurogenesis related genes.

\begin{tabular}{|c|c|c|c|}
\hline Description & Symbol & Fold Change & $p$-Value \\
\hline Acetylcholinesterase & Ache & 0.857 & 0.408505 \\
\hline Adenosine A1 receptor & Adora1 & 1.016 & 0.958737 \\
\hline Adenosine A2a receptor & Adora2a & 1.2858 & 0.364259 \\
\hline Anaplastic lymphoma kinase & Alk & 0.9632 & 0.831172 \\
\hline Amyloid beta (A4) precursor protein-binding, family B, member 1 & Apbb1 & 1.0156 & 0.930706 \\
\hline Apolipoprotein E & Apoe & 1.0062 & 0.874886 \\
\hline Amyloid beta (A4) precursor protein & App & 0.9095 & 0.20132 \\
\hline Artemin & Artn & 1.0458 & 0.845847 \\
\hline Achaete-scute complex homolog 1 (Drosophila) & Ascl1 & 0.808 & 0.038118 \\
\hline B-cell leukemia/lymphoma 2 & $\mathrm{Bcl} 2$ & 1.0486 & 0.632784 \\
\hline Brain derived neurotrophic factor & Bdnf & 0.9419 & 0.678017 \\
\hline Bone morphogenetic protein 2 & Bmp2 & 0.734 & 0.277842 \\
\hline Bone morphogenetic protein 4 & Bmp4 & 1.0426 & 0.725701 \\
\hline Bone morphogenetic protein $8 \mathrm{~b}$ & Bmp8b & 0.7345 & 0.127788 \\
\hline Cyclin-dependent kinase 5 , regulatory subunit 1 (p35) & Cdk5r1 & 0.9182 & 0.33772 \\
\hline CDK5 regulatory subunit associated protein 2 & Cdk5rap2 & 0.7886 & 0.173978 \\
\hline Cholinergic receptor, muscarinic 2 , cardiac & Chrm2 & 0.8612 & 0.481537 \\
\hline CAMP responsive element binding protein 1 & Creb1 & 1.0151 & 0.998111 \\
\hline Chemokine (C-X-C motif) ligand 1 & Cxcl1 & 2.5899 & 0.081082 \\
\hline Doublecortin & Dcx & 0.8235 & 0.012748 \\
\hline Discs, large homolog 4 (Drosophila) & Dlg4 & 0.9898 & 0.847781 \\
\hline Delta-like 1 (Drosophila) & Dll1 & 0.9084 & 0.501594 \\
\hline Dopamine receptor D2 & Drd2 & 1.1828 & 0.723812 \\
\hline Dishevelled 3, dsh homolog (Drosophila) & Dvl3 & 1.0458 & 0.480882 \\
\hline Ephrin B1 & Efnb1 & 0.9166 & 0.35916 \\
\hline Epidermal growth factor & Egf & 0.9504 & 0.69603 \\
\hline E1A binding protein p300 & Ep300 & 0.8368 & 0.062456 \\
\hline $\begin{array}{l}\text { V-erb-b2 erythroblastic leukemia viral oncogene homolog } 2, \\
\text { neuro/glioblastoma derived oncogene homolog (avian) }\end{array}$ & Erbb2 & 0.8359 & 0.236367 \\
\hline Fibroblast growth factor 2 & Fgf2 & 0.8105 & 0.055528 \\
\hline
\end{tabular}


Table 1. Cont.

\begin{tabular}{|c|c|c|c|}
\hline Description & Symbol & Fold Change & $p$-Value \\
\hline Filamin, alpha & Flna & 0.8888 & 0.349493 \\
\hline Glial cell line derived neurotrophic factor & Gdnf & 0.7991 & 0.271871 \\
\hline Glucose phosphate isomerase 1 & Gpi1 & 0.946 & 0.668135 \\
\hline Glutamate receptor, ionotropic, NMDA1 (zeta 1) & Grin1 & 0.7829 & 0.040383 \\
\hline Histone deacetylase 4 & Hdac4 & 1.0155 & 0.813732 \\
\hline Hairy and enhancer of split 1 (Drosophila) & Hes1 & 0.725 & 0.173203 \\
\hline Hairy/enhancer-of-split related with YRPW motif 1 & Hey1 & 1.1153 & 0.21879 \\
\hline Hairy/enhancer-of-split related with YRPW motif 2 & Hey2 & 0.8526 & 0.251846 \\
\hline Hairy/enhancer-of-split related with YRPW motif-like & Heyl & 0.8945 & 0.635531 \\
\hline Interleukin 3 & $\mathrm{Il} 3$ & 0.88 & 0.582914 \\
\hline Midkine & Mdk & 0.8764 & 0.145008 \\
\hline Myocyte enhancer factor $2 \mathrm{C}$ & Mef2c & 0.8003 & 0.101506 \\
\hline Myeloid/lymphoid or mixed-lineage leukemia 1 & Kmt2a & 1.0275 & 0.997062 \\
\hline Microtubule-associated protein 2 & Map2 & 0.8362 & 0.276201 \\
\hline Necdin & Ndn & 1.0382 & 0.718334 \\
\hline Norrie disease (pseudoglioma) (human) & $\mathrm{Ndp}$ & 0.9318 & 0.657985 \\
\hline Neurogenic differentiation 1 & Neurod1 & 0.8694 & 0.344025 \\
\hline Neurogenin 1 & Neurog1 & 0.62 & 0.018182 \\
\hline Neurogenin 2 & Neurog2 & 1.2238 & 0.468483 \\
\hline Neurofibromatosis 1 & Nf1 & 0.8321 & 0.06433 \\
\hline Noggin & Nog & 0.875 & 0.288031 \\
\hline Notch gene homolog 1 (Drosophila) & Notch1 & 1.0654 & 0.599656 \\
\hline Notch gene homolog 2 (Drosophila) & Notch2 & 0.9508 & 0.77945 \\
\hline Nuclear receptor subfamily 2, group E, member 3 & Nr2e3 & 1.0185 & 0.936243 \\
\hline Neuron-glia-CAM-related cell adhesion molecule & Nrcam & 0.9158 & 0.460346 \\
\hline Neuregulin 1 & Nrg1 & 0.9564 & 0.765114 \\
\hline Neuropilin 1 & Nrp1 & 0.835 & 0.406853 \\
\hline Neuropilin 2 & Nrp2 & 0.9089 & 0.406554 \\
\hline Neurotrophin 3 & Ntf3 & 0.831 & 0.299471 \\
\hline Netrin 1 & Ntn1 & 0.9076 & 0.44445 \\
\hline Odd Oz/ten-m homolog 1 (Drosophila) & Tenm1 & 0.9365 & 0.665725 \\
\hline Oligodendrocyte transcription factor 2 & Olig2 & 1.0327 & 0.853541 \\
\hline Platelet-activating factor acetylhydrolase, isoform $1 \mathrm{~b}$, subunit 1 & Pafah1b1 & 0.8419 & 0.110867 \\
\hline Par-3 (partitioning defective 3) homolog (C. elegans) & Pard3 & 0.976 & 0.878636 \\
\hline Paired box gene 3 & Pax3 & 1.0185 & 0.936243 \\
\hline Paired box gene 5 & Pax5 & 0.6895 & 0.195764 \\
\hline Paired box gene 6 & Pax6 & 0.7163 & 0.002868 \\
\hline POU domain, class 3 , transcription factor 3 & Pou3f3 & 0.8996 & 0.542927 \\
\hline POU domain, class 4 , transcription factor 1 & Pou4f1 & 0.7709 & 0.167186 \\
\hline Pleiotrophin & Ptn & 0.7296 & 0.009374 \\
\hline RAS-related C3 botulinum substrate 1 & Rac1 & 0.9743 & 0.778785 \\
\hline Roundabout homolog 1 (Drosophila) & Robo1 & 0.8688 & 0.092542 \\
\hline Reticulon 4 & Rtn4 & 1.0437 & 0.826015 \\
\hline S100 calcium binding protein A6 (calcyclin) & S100a6 & 0.9265 & 0.466286 \\
\hline S100 protein, beta polypeptide, neural & S100b & 0.9084 & 0.453236 \\
\hline Sonic hedgehog & Shh & 0.8914 & 0.445715 \\
\hline Slit homolog 2 (Drosophila) & Slit2 & 1.0868 & 0.636415 \\
\hline Superoxide dismutase 1 , soluble & Sod1 & 0.9206 & 0.228334 \\
\hline SRY-box containing gene 2 & Sox2 & 0.8523 & 0.274519 \\
\hline SRY-box containing gene 3 & Sox3 & 0.8288 & 0.392865 \\
\hline Signal transducer and activator of transcription 3 & Stat3 & 0.9089 & 0.366775 \\
\hline Transforming growth factor, beta 1 & Tgfb1 & 0.9192 & 0.351884 \\
\hline Tyrosine hydroxylase & Th & 1.2009 & 0.452233 \\
\hline Tenascin $\mathrm{R}$ & Tnr & 0.8102 & 0.04399 \\
\hline Vascular endothelial growth factor A & Vegfa & 1.107 & 0.320206 \\
\hline
\end{tabular}




\subsection{ASI Promoted Neurogenesis through CXCL1/CXCR2 Signaling Pathway}

To determine whether the effect of ASI was mediated through CXCL1/CXCR2, we utilized SB225002, an inhibitor of CXCR2. Similar to previous results, ASI treatment resulted in the significant increase of hippocampal DCX, GFAP and NeuN protein expression (Figure 7A-F). However, SB225002 reversed the promotive effects of ASI on DCX and GFAP (Figure 7A-D), and partly reversed the promotive effects of ASI on NeuN (Figure 7E,F), suggesting that ASI enhanced neurogenesis through CXCL1/CXCR2 signaling pathway.

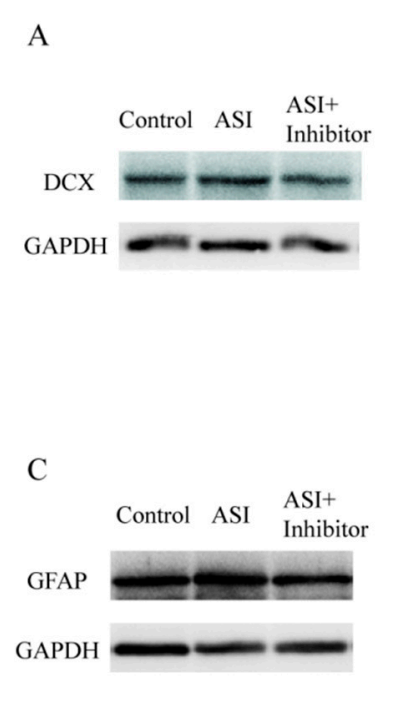

$\mathrm{E}$

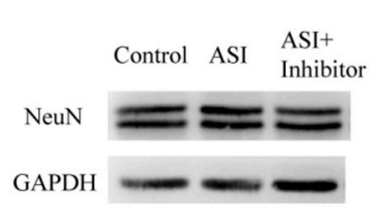

B

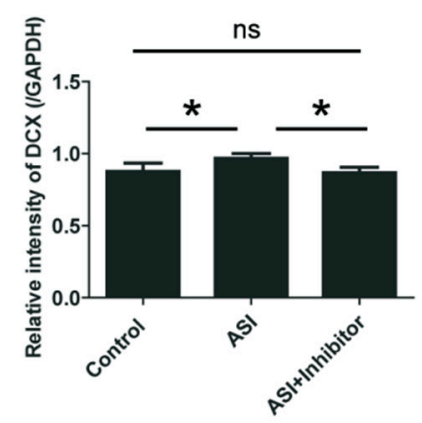

D

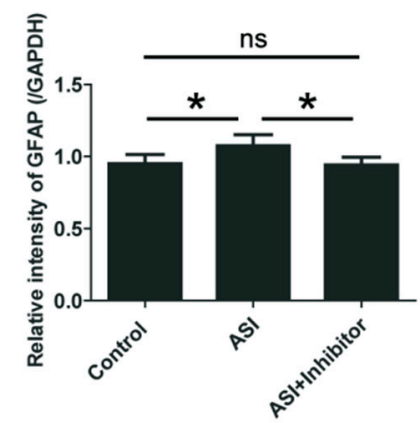

$\mathrm{F}$

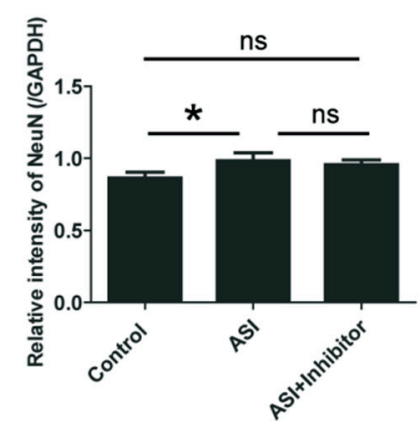

Figure 7. CXCR2 inhibitor abrogated the effects of ASI $(25 \mathrm{mg} / \mathrm{kg})$ on proliferative cells of adult neurogenesis and newly generated neurons. (A,C,E) CXCR2 inhibitor abolished the effect of ASI on DCX, GFAP and NeuN in the hippocampus of mice. (B,D,F) Gray intensity analysis of DCX, GFAP and NeuN in the hippocampus of mice ( $n=5$ /group). ${ }^{*} p<0.05$. The data are presented as mean \pm SD.

\section{Discussion}

In the present study, the effects of ASI on the hippocampal neurogenesis of mice were examined. Our data showed that ASI increased adult neurogenesis in the DGs, which was mediated by regulating the signaling transduction through the CXCL1/CXCR2 system.

Adult hippocampal neurogenesis is a complex process, in which new excitatory granule cells are generated in the DGs, particularly in the subgranular zone (SGZ). Hippocampal neurogenesis originates from a population of neuronal precursor cells in the SGZ [26]. They give rise to intermediate progenitor cells with glial or neuronal phenotype [1]. In our experiments, $\mathrm{BrdU}^{+}$cells and $\mathrm{DCX}^{+}$ cells were significantly increased in the ASI group of mice. Meanwhile, the numbers of $\mathrm{BrdU}^{+} / \mathrm{DCX}^{+}$ 
cells, $\mathrm{BrdU}^{+} / \mathrm{GFAP}^{+}$cells and $\mathrm{BrdU}^{+} / \mathrm{NeuN}^{+}$cells were also increased by ASI treatment, suggesting a promotive effect of the compound on adult neurogenesis at multiple levels (Figure 4). Although the radial glia-like cells (also called type 1 hippocampal progenitors) express the astrocyte marker GFAP, these cells are morphologically and functionally different from mature astrocytes. The expression of GFAP protein in the hippocampus could not distinguish between them.

Several lines of evidence indicate that CXCL1/CXCR2 signaling plays an important role in neurogenesis. For instance, CXCL1 stimulation enhances the proliferative response of the rat's immature spinal cord oligodendrocyte precursors to platelet derived growth factor $[27,28]$ as well as elevates the number of dopaminergic neurons in rat ventral midbrain precursor and neurosphere cultures [29]. Normally functioning CXCR2 seems to protect neurons from injury. In brain trauma, neuronal CXCR2 downregulation is suggested to render neurons more vulnerable to injury [30]. While CXCR2 ligands macrophage inflammatory protein 2 (MIP-2), CXCL1 and CXCL8 are indicated to protect hippocampal neurons against beta-amyloid (1-42) induced death [31]. It has been reported that CXCR2 antagonist SB225002 significantly attenuated microglial activation and blood brain barrier (BBB) damage, increased myelination, and reduced astrogliosis in the white matter [32]. As a result, we considered that SB225002 could pass through the BBB. Our experiments showed that ASI boosted hippocampal CXCL1 and CXCR2 expression at both mRNA and protein levels. In the presence of CXCR2 inhibitor, the effect of ASI on the protein expression of DCX, GFAP and NeuN could be abrogated more or less. Therefore, the enhanced CXCL1/CXCR2 signaling transduction at least partly led to the promotive effects of ASI on adult neurogenesis in the hippocampal DGs of mice.

One limitation of the present study is that we did not evaluate the characteristics of all types of newborn cells to conclusively ascertain the early markers for neuronal lineage. Moreover, it remains to be determined about how the actions of ASI regulated the adult neurogenesis through CXCL1/CXCR2 signaling transduction. There was another neurogenesis related gene Neurog 1 showed a significant change in expression between the treated and control (Figure 5D) groups, but due to its minimal change, we would like invest it in the future.

Our results indicated that ASI modulated the homeostasis of the CXCL1/CXCR2 system, which might be responsible for the increased neurogenesis in the hippocampal DGs of mice. Neurogenesis of the adult brain is a very interesting phenomenon. Many studies over the last 20 years have aimed to decipher the role of the phenomenon in the brain [33]. With so many functions ascribed to the adult brain neurogenesis, ASI may have a beneficial effect on the recovery of brain dysfunction.

\section{Materials and Methods}

\subsection{Animal and Drug Administration}

Male C57BL/ 6 mice (18-22 g, 6 weeks old) were provided by the Laboratory Animal Center of Shanghai University of Traditional Chinese Medicine (SHUTCM, Shanghai, China). The mice were housed under a $12 \mathrm{~h}$ light $/ 12 \mathrm{~h}$ dark cycle at room temperature $\left(25 \pm 1^{\circ} \mathrm{C}\right)$ and fed with food and water ad libitum. All experiments on animals were performed according to the protocol approved by Animal Care and Use Committee of SHUTCM and all animals received humane care (Ethical approval no. SZY201607003). Half of the mice were injected intraperitoneally (i.p.) with ASI $(25 \mathrm{mg} / \mathrm{kg}$, $40 \%$ 1,2-Propanediol $+1 \%$ Polyethylene glycol $+5 \%$ Ethanol in phosphate buffer saline solution, i.p.) for two weeks, while the other half of mice served as the control and were administered with solvent. Among the animals, eight mice (four in control group and four in ASI group) used for IHC analysis were additionally treated with 5-bromo-2'-deoxyuridine (BrdU, Sigma Aldrich, St. Lpuis, $\mathrm{MO}$, USA, cat\#B5002,) to label endogenous proliferating cells. The BrdU treated mice were injected intraperitoneally with BrdU (50 mg/ $\mathrm{kg}$ ) once every two days for two weeks, and were sacrificed $18 \mathrm{~h}$ following the last BrdU injection. To evaluate the influence of CXCR2 inhibitor on the promotive effect of ASI, a potent and selective antagonist of CXCR2 (SB225002, Selleck, Houston, TX, USA) was used 
$(4 \mathrm{mg} / \mathrm{kg})$ together with ASI for two weeks. At last, the mice after drug treatment were sacrificed and their hippocampi were dissected, snap frozen in liquid nitrogen and stored at $-80{ }^{\circ} \mathrm{C}$ until analysis.

\subsection{Immunohistochemistry}

For the histological analysis, animals were anesthetized with $2 \%$ pentobarbital sodium and perfused transcardially with $0.1 \mathrm{M}$ phosphate buffer (PBS, $\mathrm{pH} 7.4$ ) followed by $4 \%$ paraformaldehyde. The brains were dissected and fixed in the same fixative overnight. Brain tissues were dehydrated by infiltration with $10 \%$ and $30 \%$ sucrose, respectively, for $24 \mathrm{~h}$ at $4{ }^{\circ} \mathrm{C}$. Then, they were serially sectioned into $20 \mu \mathrm{m}$ coronal slices containing the dentate gyrus of hippocampus from Bregma -1.00 to $-2.92 \mathrm{~mm}$ according to the mouse brain atlas [34]. For each mouse, there were ninety-six slices, sixteen of which, with an interval of $120 \mu \mathrm{m}$, were chosen for immunohistochemistry analysis. The final total positive cell numbers in each mouse were calculated as six-fold the sum of that in the sixteen slices.

To examine the cell proliferation and differentiation, double immunofluorescence staining for BrdU and DCX/GFAP/NeuN was performed. The free-floating sections were washed with PBS, immersed in $10 \%$ donkey serum and $0.3 \%$ Triton X-100 in $0.1 \mathrm{M} \mathrm{PBS}$ for $1 \mathrm{~h}$, and incubated with rabbit anti-DCX antibody (1:400; v/v, Santa Cruz Biotechnology, Santa Cruz, CA, USA, cat\#4604)/mouse anti-GFAP antibody (1:400; Santa Cruz Biotechnology, cat\#3670)/rabbit anti-NeuN antibody (1:400; Santa Cruz Biotechnology, cat\#12943) at $4{ }^{\circ} \mathrm{C}$ overnight. The sections were then incubated with Alexa-labeled donkey anti-rabbit or anti-mouse antibody at room temperature for $1 \mathrm{~h}$. For BrdU immunostaining, the sections were incubated in $2 \mathrm{~N} \mathrm{HCl}$ for $30 \mathrm{~min}$ at $37{ }^{\circ} \mathrm{C}$ to denature DNA, and neutralized in $0.1 \mathrm{M}$ borate buffer $(\mathrm{pH}$ 8.4) for $10 \mathrm{~min}$. After being washed with PBS, the sections were incubated with $0.1 \%$ trypsin for $5 \mathrm{~min}$ at $37^{\circ} \mathrm{C}$ followed by $10 \%$ donkey serum and $0.3 \%$ Triton X-100 in 0.1 M PBS. Thereafter, the sections were incubated with rat anti-BrdU antibody (1:150; Bio-Rad, Hercules, CA, USA, cat\#OBT0030G) at $4{ }^{\circ} \mathrm{C}$ overnight, then washed with PBS and incubated with Alexa-labeled donkey anti-rat antibody at room temperature for $1 \mathrm{~h}$. Finally, all sections were washed and mounted on slides using gold anti-fade reagent with DAPI (Life Technologies, Gaithersburg, MD, USA, cat\#P36935). The fluorescent pictures were taken with the confocal microscope system (FV10i Fluo view, Olympus, Japan).

\section{3. $R T^{2}$ Profiler PCR Array Analysis}

Mouse Neurogenesis $\mathrm{RT}^{2}$ Profiler PCR arrays were carried out on 384-well plates containing primers for 84 pathway/disease/function genes related with neurogenesis, 5 house keeping genes, 1 genomic DNA contamination control, 3 reverse transcription quality controls and 3 PCR reaction quality controls. Total RNA was extracted from hippocampus using RNasy ${ }^{\circledR}$ Mini Kit (Qiagen, Duesseldorf, Germany, cat\#74104) and reverse transcribed into cDNA using RT ${ }^{2}$ First Strand kit (Qiagen, cat\#330401). cDNA was mixed with RT $^{2}$ SYBR Green/ROX PCR MasterMix (Qiagen, cat\#330521). The mixture was subsequently added into each well of the 384-well plates (Qiagen, cat\#PAMM-404Z) and quantitative PCR was performed. Data was analyzed using $2^{\wedge(-\mathrm{CT})}$ method.

\subsection{Real-Time PCR}

To confirm the immunohistochemistry and PCR arrays' results, total RNAs from the hippocampi of mice were extracted using Trizol according to the manufacturer's instructions (Life Technologies, Gaithersburg, MD, USA). The RNAs were then reversely transcribed into cDNA with Revert Aid First Strand cDNA Synthesis kit (Fermentas, Burlington, ON, Canada). The synthesized cDNA was used as templates for quantitative real-time PCR with Universal SYBR Green/ROX qPCR Master Mix (Roche, Basel, Switzerland). Primers used are listed in Table 2. 
Table 2. Sequences of primers for quantitative PCR.

\begin{tabular}{ccc}
\hline Gene & Forward Primer & Reverse Primer \\
\hline Ascl1 & GTCACAAGTCAGCGGCCAAGCA & TTCTTGTTGGCCGCGCCGTT \\
CXCL1 & GCCAATGAGCTGCGCTGTCAGT & AAGGCAAGCCTCGCGACCATTC \\
CXCR2 & ATGCTGTCCCATGCCACTCAGAGA & CCATTTACTTTAGATGCAGCCCAGACA \\
Dcx & CATCTAGAAATATGAGAGGGTCACGGATG & TCTTCCAGTTCATCCATGCTTCCAAT \\
Neurog1 & CCTCTCCGGGGCATCGAATGTT & TGAGCTTGGTGTCGTCGGGGAA \\
GAPDH & ATGTGTCCGTCGTGGATCTGA & ATGCCTGCTTCACCACCTTCT \\
Grin1 & CAAGCCCAACGCCATACAGATGG & AGCAACGTCTCCAGGCGCTTCT \\
Pax6 & CCAGGGCAATCGGAGGGAGTAA & CGCCCATCTGTTGCTTTTCGCTA \\
Ptn & GCAACGTAGAAAATTTGCAGCTGCCTTC & TCTCTGAGTCTTCATGGTCTGTTTGCAC \\
Tnr & AGGTGACTACAGAAAGGGCTCAGAGACA & GCTCAGCAGTTCCTGCAGTACCTGG \\
\hline
\end{tabular}

\subsection{Western Blotting Analysis}

To examine the effect of ASI on the expression of proteins, samples from hippocampi were homogenized, sonicated, and subjected to Western blotting analysis. Twenty micrograms of proteins from each sample were separated on 10-15\% SDS-PAGE. After being transferred onto PVDF membranes, the proteins were incubated with respective primary antibodies against DCX (1:1000, $v / v), \operatorname{GFAP}(1: 1000, v / v), \operatorname{NeuN}(1: 1000, v / v), \operatorname{CXCR2}(1: 1000 ; v / v$, Abcam cat\#14935) horseradish peroxidase-conjugated secondary antibodies sequentially as described previously [21]. The protein bands were visualized by an ECL-prime kit and quantified with ImageJ 1.46r software (NIH, Bethesda, MD, USA).

\subsection{ELISA Analysis}

To detect the effect of ASI on CXCL1, concentrations of mouse chemokine in serum and hippocampi were measured using a CXCL1-specific ELISA kit (Boster Biological Technology, Wuhan, China), following the manufacturer's instructions.

\subsection{Statistical Analysis}

All data are presented as mean $\pm \mathrm{SD}$. The difference of measurement data was evaluated by unpaired t-test and one-way ANOVA with Tukey multiple comparison test; the difference of count data was evaluated by Kruskal-Wallis test. SPSS 18.0 (SPSS Inc., Chicago, IL, USA) was used for analysis. The value of $p<0.05$ was regarded as statistically significant.

\section{Conclusions}

We have demonstrated that that ASI promoted adult neurogenesis in hippocampal dentate gyrus of mouse, which was mediated by regulating the signaling transduction through the CXCL1/CXCR2 system. Further studies of the effect of ASI on neurogenesis-related brain function or behavior are needed in order to replicate our observations and to extend the evidence on the effect of therapy on CXCL1/CXCR2 system. Therefore, ASI may be a potential therapeutic drug for the recovery of brain dysfunction.

Author Contributions: Data curation, Y.L.; Formal analysis, Y.L.; Funding acquisition, F.H. and X.W.; Investigation, F.H., Y.L., L.Q., H.D., H.W. and Q.Z.; Methodology, L.Q. and H.S.; Supervision, Z.H. and X.W.; Writing-original draft, F.H.; and Writing — review and editing, X.W.

Funding: This work was sponsored by National Natural Science Foundation of China (81673626 and 81703734), Shanghai Sailing Program (17YF1417700), Natural Science Foundation of Shanghai (17ZR1430200) and Educational Commission of Shanghai in China (2015YSN15).

Conflicts of Interest: There are no conflicts of interest to declare. 


\section{References}

1. Kempermann, G.; Song, H.; Gage, F.H. Neurogenesis in the adult hippocampus. CSH Perspect. Med. 2015, 5, a018812. [CrossRef] [PubMed]

2. Kuhn, H.G.; Dickinson-Anson, H.; Gage, F.H. Neurogenesis in the dentate gyrus of the adult rat: Age-related decrease of neuronal progenitor proliferation. J. Neurosci. Off. Soc. Neurosci. 1996, 16, 2027-2033. [CrossRef]

3. Ramirez-Amaya, V.; Marrone, D.F.; Gage, F.H.; Worley, P.F.; Barnes, C.A. Integration of new neurons into functional neural networks. J. Neurosci. Off. Soc. Neurosci. 2006, 26, 12237-12241. [CrossRef] [PubMed]

4. Shin, J.H.; Kim, Y.N.; Kim, I.Y.; Choi, D.H.; Yi, S.S.; Seong, J.K. Increased cell proliferations and neurogenesis in the hippocampal dentate gyrus of ahnak deficient mice. Neurochem. Res. 2015, 40, 1457-1462. [CrossRef] [PubMed]

5. Dupret, D.; Revest, J.M.; Koehl, M.; Ichas, F.; De Giorgi, F.; Costet, P.; Abrous, D.N.; Piazza, P.V. Spatial relational memory requires hippocampal adult neurogenesis. PLoS ONE 2008, 3, e1959. [CrossRef] [PubMed]

6. Imayoshi, I.; Sakamoto, M.; Ohtsuka, T.; Takao, K.; Miyakawa, T.; Yamaguchi, M.; Mori, K.; Ikeda, T.; Itohara, S.; Kageyama, R. Roles of continuous neurogenesis in the structural and functional integrity of the adult forebrain. Nat. Neurosci. 2008, 11, 1153-1161. [CrossRef] [PubMed]

7. Saxe, M.D.; Battaglia, F.; Wang, J.W.; Malleret, G.; David, D.J.; Monckton, J.E.; Garcia, A.D.; Sofroniew, M.V.; Kandel, E.R.; Santarelli, L.; et al. Ablation of hippocampal neurogenesis impairs contextual fear conditioning and synaptic plasticity in the dentate gyrus. Proc. Natl. Acad. Sci. USA 2006, 103, 17501-17506. [CrossRef] [PubMed]

8. Yoshimura, T.; Matsushima, K.; Tanaka, S.; Robinson, E.A.; Appella, E.; Oppenheim, J.J.; Leonard, E.J. Purification of a human monocyte-derived neutrophil chemotactic factor that has peptide sequence similarity to other host defense cytokines. Proc. Natl. Acad. Sci. USA 1987, 84, 9233-9237. [CrossRef] [PubMed]

9. Bonavia, R.; Bajetto, A.; Barbero, S.; Pirani, P.; Florio, T.; Schettini, G. Chemokines and their receptors in the cns: Expression of cxcl12/sdf-1 and cxcr4 and their role in astrocyte proliferation. Toxicol. Lett. 2003, 139, 181-189. [CrossRef]

10. Araujo, D.M.; Cotman, C.W. Trophic effects of interleukin-4, -7 and -8 on hippocampal neuronal cultures: Potential involvement of glial-derived factors. Brain Res. 1993, 600, 49-55. [CrossRef]

11. Hesselgesser, J.; Horuk, R. Chemokine and chemokine receptor expression in the central nervous system. J. Neurovirol. 1999, 5, 13-26. [CrossRef] [PubMed]

12. Tsai, H.H.; Frost, E.; To, V.; Robinson, S.; Ffrench-Constant, C.; Geertman, R.; Ransohoff, R.M.; Miller, R.H. The chemokine receptor cxcr2 controls positioning of oligodendrocyte precursors in developing spinal cord by arresting their migration. Cell 2002, 110, 373-383. [CrossRef]

13. Fu, J.; Wang, Z.; Huang, L.; Zheng, S.; Wang, D.; Chen, S.; Zhang, H.; Yang, S. Review of the botanical characteristics, phytochemistry, and pharmacology of Astragalus membranaceus (HUANGQI). Phytother. Res. PTR 2014, 28, 1275-1283. [CrossRef] [PubMed]

14. Zhang, Z.G.; Wu, L.; Wang, J.L.; Yang, J.D.; Zhang, J.; Zhang, J.; Li, L.H.; Xia, Y.; Yao, L.B.; Qin, H.Z.; et al. Astragaloside iv prevents mpp(+)-induced sh-sy5y cell death via the inhibition of bax-mediated pathways and ros production. Mol. Cell. Biochem. 2012, 364, 209-216. [CrossRef] [PubMed]

15. Li, X.; Wang, X.; Han, C.; Wang, X.; Xing, G.; Zhou, L.; Li, G.; Niu, Y. Astragaloside iv suppresses collagen production of activated hepatic stellate cells via oxidative stress-mediated p38 mapk pathway. Free Radic. Biol. Med. 2013, 60, 168-176. [CrossRef] [PubMed]

16. Hu, J.Y.; Han, J.; Chu, Z.G.; Song, H.P.; Zhang, D.X.; Zhang, Q.; Huang, Y.S. Astragaloside iv attenuates hypoxia-induced cardiomyocyte damage in rats by upregulating superoxide dismutase-1 levels. Clin. Exp. Pharmacol. Physiol. 2009, 36, 351-357. [CrossRef] [PubMed]

17. Luo, Y.; Qin, Z.; Hong, Z.; Zhang, X.; Ding, D.; Fu, J.H.; Zhang, W.D.; Chen, J. Astragaloside iv protects against ischemic brain injury in a murine model of transient focal ischemia. Neurosci. Lett. 2004, 363, $218-223$. [CrossRef] [PubMed]

18. Li, M.; Qu, Y.Z.; Zhao, Z.W.; Wu, S.X.; Liu, Y.Y.; Wei, X.Y.; Gao, L.; Gao, G.D. Astragaloside iv protects against focal cerebral ischemia/reperfusion injury correlating to suppression of neutrophils adhesion-related molecules. Neurochem. Int. 2012, 60, 458-465. [CrossRef] [PubMed] 
19. Liu, G.; Song, J.; Guo, Y.; Wang, T.; Zhou, Z. Astragalus injection protects cerebral ischemic injury by inhibiting neuronal apoptosis and the expression of jnk3 after cerebral ischemia reperfusion in rats. $B B F$ 2013, 9, 36. [CrossRef] [PubMed]

20. Qu, Y.Z.; Li, M.; Zhao, Y.L.; Zhao, Z.W.; Wei, X.Y.; Liu, J.P.; Gao, L.; Gao, G.D. Astragaloside iv attenuates cerebral ischemia-reperfusion-induced increase in permeability of the blood-brain barrier in rats. Eur. J. Pharmacol. 2009, 606, 137-141. [CrossRef] [PubMed]

21. He, Y.; Du, M.; Gao, Y.; Liu, H.; Wang, H.; Wu, X.; Wang, Z. Astragaloside iv attenuates experimental autoimmune encephalomyelitis of mice by counteracting oxidative stress at multiple levels. PLOS ONE 2013, 8, e76495. [CrossRef] [PubMed]

22. Kim, S.; Kang, I.H.; Nam, J.B.; Cho, Y.; Chung, D.Y.; Kim, S.H.; Kim, J.S.; Cho, Y.D.; Hong, E.K.; Sohn, N.W.; et al. Ameliorating the effect of astragaloside iv on learning and memory deficit after chronic cerebral hypoperfusion in rats. Molecules 2015, 20, 1904-1921. [CrossRef] [PubMed]

23. Li, M.; Li, H.; Fang, F.; Deng, X.; Ma, S. Astragaloside IV attenuates cognitive impairments induced by transient cerebral ischemia and reperfusion in mice via anti-inflammatory mechanisms. Neurosci. Lett. 2017, 639, 114-119. [CrossRef] [PubMed]

24. Hu, H.; Yang, R.; Jin, G.; Zhang, X.; Xia, H.; Xu, Y. Effect of astragaloside IV on neural stem cell transplantation in alzheimer's disease rat models. Evid.-Based Complement. Altern. Med. 2016, 2016, 3106980.

25. Huang, P.; Lu, X.; Yuan, B.; Liu, T.; Dai, L.; Liu, Y.; Yin, H. Astragaloside iv alleviates e. Coli-caused peritonitis via upregulation of neutrophil influx to the site of infection. Int. Immunopharmacol. 2016, 39, 377-382. [CrossRef] [PubMed]

26. Deng, W.; Aimone, J.B.; Gage, F.H. New neurons and new memories: How does adult hippocampal neurogenesis affect learning and memory? Nat. Rev. Neurosci. 2010, 11, 339-350. [CrossRef] [PubMed]

27. Robinson, S.; Tani, M.; Strieter, R.M.; Ransohoff, R.M.; Miller, R.H. The chemokine growth-regulated oncogene-alpha promotes spinal cord oligodendrocyte precursor proliferation. J. Neurosci. Off. J. Soc. Neurosci. 1998, 18, 10457-10463. [CrossRef]

28. Wu, Q.; Miller, R.H.; Ransohoff, R.M.; Robinson, S.; Bu, J.; Nishiyama, A. Elevated levels of the chemokine gro-1 correlate with elevated oligodendrocyte progenitor proliferation in the jimpy mutant. J. Neurosci. Off. J. Soc. Neurosci. 2000, 20, 2609-2617. [CrossRef]

29. Edman, L.C.; Mira, H.; Erices, A.; Malmersjo, S.; Andersson, E.; Uhlen, P.; Arenas, E. Alpha-chemokines regulate proliferation, neurogenesis, and dopaminergic differentiation of ventral midbrain precursors and neurospheres. Stem Cells 2008, 26, 1891-1900. [CrossRef] [PubMed]

30. Valles, A.; Grijpink-Ongering, L.; de Bree, F.M.; Tuinstra, T.; Ronken, E. Differential regulation of the cxcr2 chemokine network in rat brain trauma: Implications for neuroimmune interactions and neuronal survival. Neurobiol. Dis. 2006, 22, 312-322. [CrossRef] [PubMed]

31. Watson, K.; Fan, G.H. Macrophage inflammatory protein 2 inhibits beta-amyloid peptide (1-42)-mediated hippocampal neuronal apoptosis through activation of mitogen-activated protein kinase and phosphatidylinositol 3-kinase signaling pathways. Mol. Pharmacol. 2005, 67, 757-765. [CrossRef] [PubMed]

32. Wang, L.Y.; Tu, Y.F.; Lin, Y.C.; Huang, C.C. Cxcl5 signaling is a shared pathway of neuroinflammation and blood-brain barrier injury contributing to white matter injury in the immature brain. J. Neuroinflam. 2016, 13, 6. [CrossRef] [PubMed]

33. Filipkowski, R.K.; Kaczmarek, L. Severely impaired adult brain neurogenesis in cyclin d2 knock-out mice produces very limited phenotypic changes. Prog. Neuro-Psychopharm. Biol. Psychiatry 2018, 80, 63-67. [CrossRef] [PubMed]

34. Paxinos, G.; Franklin, K.B.J.; Franklin, K.B.J. The Mouse Brain in Stereotaxic Coordinates, 2nd ed.; Academic Press: San Diego, CA, USA, 2001.

Sample Availability: Samples of the compounds are available from the authors. 